\title{
Effect of bronchoconstrictor aerosols on the alveolar plateau of the single breath $\mathrm{O}_{2}$ test
}

\author{
D. C. STANESCU ${ }^{1}$, D. B. TECULESCU, R. PACURARU, \\ A N D V. POPA
}

From the Cardiopulmonary Laboratory and Allergy Unit, Department of Occupational Diseases, Hospital Colentina and Institute of Hygiene, Bucharest, Rumania

In 17 subjects with bronchial asthma and chronic bronchitis measurements of the uneven ventilation using the single breath oxygen test, F.E.V.1.0 and V.C. were performed before and after acetylcholine or allergen nebulization. An increase of the alveolar slope was noticed in five out of the seven patients with induced bronchospasm and a decrease in the remaining two. In two other subjects moderate dyspnoea not reflected by spirographic tests was accompanied by a definite increase of the $\mathrm{N}_{2}$ gradient. One patient experienced a severe asthmatic attack after acetylcholine without significant increase of the $\mathbf{N}_{2}$ gradient. In the last seven subjects the spirographic tests were not impaired but the $\mathrm{N}_{2}$ gradient rose to a significant level in three. The various implications of these results are discussed. In one subject the alveolar nitrogen concentration decreased after acetylcholine with a concomitant increase in the residual volume. This finding was assumed to be the result of either a failure of inspired oxygen to mix with alveolar nitrogen or a decreased available lung space.

In the last few years bronchial inhalation tests have gained widespread acceptance in the diagnosis of bronchial asthma (Herxheimer, 1951; Tiffeneau, 1959 ; Nilsson and Kaude, 1960 ; McAllen, 1961; Marcelle and Petit, 1965; Kim, 1965). Induced bronchospasm, using either bronchoconstrictive drugs (acetylcholine, carbachol, histamine) or allergens, is currently evidenced by spirographic tests (Citron, Frankland, and Sinclair, 1958 ; Fagerberg, 1966) or more elaborate methods, as in the determination of pulmonary mechanics (Colldahl, Nisell, Ripe, and Svanborg, 1960 ; Bernstein, Kreindler, and Sugeman, 1964 ; Scherrer, 1966) or tests of the uneven distribution of inspired air (Bouhuys, Georg, Jönsson, Lundin, and Lindell, 1960a ; Bouhuys, Jönsson, Lichtneckert, Lindell, Lundgren, Lundin, and Ringquist, 1960b ; Petit, 1965).

Previous work has stressed the value of the single breath oxygen test as a simple and objective method for detecting minor obstructive impairment (Olsen and Gilson, 1960 ; Malmberg, Simonsson, and Berglund, 1963 ; Stanescu, Teculescu, Pacuraru, and Gavrilescu, 1968a).

The purpose of this paper is to investigate the effect of induced bronchospasm on the distribu-

${ }^{1}$ Reprint requests to Dr. D. C. Stanescu, Clinica de Boli Profesionale, Spitalul Colentina, Bucharest 10, Rumania tion of alveolar ventilation studied by the single breath $\mathrm{O}_{2}$ test ; and subsequently to find whether or not this method is a reliable index in the appreciation of the inhalation test.

\section{MATERIALS AND METHODS}

Of the 17 subjects, most were in-patients; the others were out-patients studied for longer periods in the allergy unit. The patients had a clinical diagnosis of bronchial asthma and chronic bronchitis (Medical Research Council, 1965). Most of the patients were free of symptoms at the time of the study. No patient was receiving steroids either before or during the tests: bronchodilators were withdrawn the day before the test.

All patients had received inhalation tests previously with the following results: nine patients had a positive response to inhaled bronchoconstrictive drugs; in three patients, although the decrease of the forced expiratory volume was insignificant, slight dyspnoea after nebulization cast some doubt on the result of the inhalation test. In the remaining five patients there was a negative inhalation test without clinical complaint.

Tests of respiratory function were done in the morning in the sitting position. Vital capacity and forced expiratory volume were measured on a 9-litre spirometer (Pulmotest Godart). The distribution of alveolar ventilation was studied by the single breath 
oxygen test of Comroe and Fowler (1951), standardized by Kjellmer, Sandqvist, and Berglund (1959). Nitrogen concentrations were measured using a nitrogen analyser (Nitrograph Godart), with a $90 \%$ delay time for a square-wave change in nitrogen concentration from 80 to $0 \%$ of 0.34 sec., and a $90 \%$ response time of $0.09 \mathrm{sec}$. The nitrogen meter was calibrated between each series of experiments with room air and 99.5\% oxygen and the calibration curve of the apparatus was tested on several occasions with different mixtures of nitrogen in oxygen (analysed with a Van Slyke apparatus). The output of the analyser was displayed on a direct writing multichannel recorder (Multiscriptor 9400/6 Hellige) at a paper speed of $50 \mathrm{~mm}$./second. The assembly system is presented diagrammatically in the Figure. The subject was coupled in the circuit at the end of a normal expiration and inspired 1,000 $( \pm 50) \mathrm{ml}$. oxygen (A.T.P.S.) from the spirometer $S_{1}$ and expired (with a mean expiratory flow rate of 30-60 1./min.) without pause into a second spirometer $S_{2}$; the instrumental dead space (from the $T$ tap to the patient's lips) was $100 \mathrm{ml}$. Before each series the dead space between valves $V_{1}$ and $V_{2}$ was flushed with oxygen. Two electric contacts on the counterweight of the $S_{2}$ spirometer indicated 750 and $1,250 \mathrm{ml}$. (A.T.P.S.) of expirate. These signals were displayed simultaneously with the $\mathrm{N}_{2}$ concentrations on the second channel of the recorder. The difference of nitrogen concentration between $1,250 \mathrm{ml}$. and 750 $\mathrm{ml}$. expired volume was measured and is referred to as $\mathrm{N}_{2}$ gradient. Tests were discarded and repeated when $(a)$ a precise volume of oxygen was not inspired, (b) the expiratory flow rate was not within the required limits, (c) the $\mathrm{N}_{2}$ plateau was wavy, or $(d)$ a pause was made between the inspiration and expiration. All measurements of the $\mathbf{N}_{2}$ gradient were performed by the same investigator.

Aerosols of $1 \%$ acetylcholine or Bencard inhalatory allergens (diluted to $1 / 10$ ) were produced with a nebulizer. Patients directed the aerosol stream into the mouth and breathed deeply for 3 minutes. The amount of bronchoconstrictive agents was not measured, since only a bronchospastic response was intended.

In each subject the experiment started with five single breath tests, at least 3 minutes elapsing between tests. The subjects then performed a vital capacity and a forced expiratory volume and these were recorded, after which the aerosol inhalation started. A further five single breath $\mathrm{O}_{2}$ tests and spirographic measurements were made immediately after acetylcholine nebulization or 30-60 minutes after allergens. This sequence of measurements was adopted in order to prevent a possible alteration of the intrapulmonary distribution due to forced inspiratory and expiratory manœuvres. The mean expiratory flow during the single breath $\mathrm{O}_{2}$ test was maintained before and after nebulization in each subject at a similar level.

Each subject acted as his own control. The five measurements of the $\mathbf{N}_{2}$ gradient before nebulization were compared with the corresponding five measurements after nebulization, and the statistical significance of the difference of means was ascertained in each subject with the Student $t$ test.

\section{RESULTS}

In Table I are presented the age, sex, vital capacity, forced expiratory volume, and F.E.V.:-1.0/ V.C. of the 20 subjects investigated. In Table II the mean nitrogen concentrations at $750 \mathrm{ml}$. and $1,250 \mathrm{ml}$. expirate volume and their difference (the $\mathrm{N}_{2}$ gradient) before and after nebulization are given together with the per cent decrease of vital capacity and forced expiratory volume.

Patients 1, 7, 12, and 15 received allergens : acetylcholine was administered to the remaining 13.

A slight obstructive ventilatory impairment (F.E.V.1.0 $/$ V.C. lower than $70 \%$ ) was present in 11 subjects. Six patients had an increased initial $\mathrm{N}_{2}$ gradient (beyond the upper normal limit (Sandqvist and Kjellmer, 1960 ; Stanescu, Teculescu, and Pacuraru, 1968b) ).

$\mathbf{N}_{2}$ gradient was considered significantly different from the starting level when $P$ was less than 0.05 . In 10 normals the repeatability of the $N_{2}$ gradient before and after an hour gave a mean difference of zero $\pm 0.36 \% \quad N_{2}$ (standard devia-

FIGURE. Apparatus assembly.

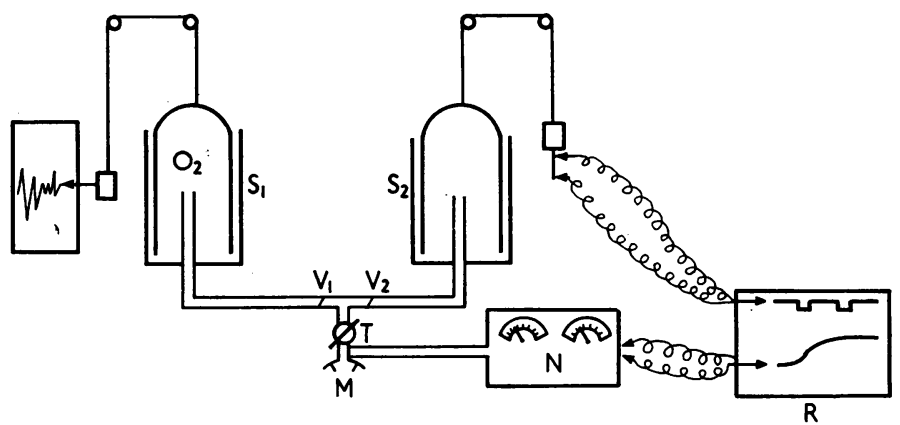


T A B LE I

\begin{tabular}{|c|c|c|c|c|c|}
\hline Subject & $\underset{\text { (years) }}{\text { Age }}$ & Sex & $\begin{array}{l}\text { V.C. } \\
\text { (ml.) }\end{array}$ & $\underset{(\mathrm{ml} .)}{\text { F.E.V. }}$ & F.E.V.1.o/V.C \\
\hline $\begin{array}{l}1 \\
2 \\
2 \\
3 \\
4 \\
5 \\
6 \\
7 \\
8 \\
9 \\
10 \\
11 \\
12 \\
13 \\
14 \\
15 \\
16 \\
17\end{array}$ & $\begin{array}{l}33 \\
64 \\
64 \\
43 \\
44 \\
60 \\
38 \\
36 \\
32 \\
30 \\
43 \\
28 \\
39 \\
32 \\
37 \\
31 \\
38 \\
32\end{array}$ & $\begin{array}{l}\mathbf{M} \\
\mathbf{M} \\
\mathbf{M} \\
\mathbf{M} \\
\mathbf{F} \\
\mathbf{M} \\
\mathbf{F} \\
\mathbf{F} \\
\mathbf{M} \\
\mathbf{M} \\
\mathbf{F} \\
\mathbf{M} \\
\mathbf{M} \\
\mathbf{F} \\
\mathbf{F} \\
\mathbf{M} \\
\mathbf{F} \\
\mathbf{F}\end{array}$ & $\begin{array}{l}4,650 \\
3,150 \\
3,600 \\
4,300 \\
2,850 \\
3,100 \\
2,450 \\
2,750 \\
3,800 \\
6,050 \\
2,550 \\
5,100 \\
3,000 \\
2,550 \\
4,200 \\
4,400 \\
3,250 \\
3,400\end{array}$ & $\begin{array}{l}3,200 \\
2,500 \\
2,450 \\
2,700 \\
1,850 \\
2,150 \\
1,650 \\
1,600 \\
2,700 \\
4,700 \\
1,750 \\
3,300 \\
1,800 \\
1,600 \\
3,100 \\
3,000 \\
2,600 \\
2,500\end{array}$ & $\begin{array}{l}68 \cdot 5 \\
78 \cdot 5 \\
68 \cdot 0 \\
63 \cdot 0 \\
66 \cdot 0 \\
69 \cdot 5 \\
67 \cdot 5 \\
58 \cdot 5 \\
71 \cdot 0 \\
78.0 \\
68 \cdot 5 \\
64 \cdot 0 \\
59 \cdot 5 \\
63 \cdot 0 \\
74 \cdot 5 \\
68 \cdot 0 \\
79 \cdot 0 \\
73 \cdot 5\end{array}$ \\
\hline
\end{tabular}

T A B L E I I

\begin{tabular}{|c|c|c|c|c|c|c|c|c|}
\hline Subject & \multicolumn{2}{|c|}{$\begin{array}{c}\% \mathrm{~N}_{2} \\
750 \mathrm{ml} \\
\text { B }\end{array}$} & \multicolumn{2}{|c|}{$\underset{B}{1,250} \underset{A}{\%} \mathrm{~N}_{2}$} & \multicolumn{2}{|c|}{$\mid \begin{array}{c}\mathrm{N}_{2} \text { Gradient } \\
\text { B } \\
\end{array}$} & $\begin{array}{r}\text { V.C. \% } \\
\text { Decrease }\end{array}$ & $\begin{array}{c}\text { F.E.V.1.0 } \\
\% \\
\text { Decrease }\end{array}$ \\
\hline $\begin{array}{c}1 \\
2 \\
2 \text { bis } \\
3 \\
4 \\
5 \\
6 \\
7 \\
8 \\
9 \\
10 \\
11 \\
12 \\
13 \\
14 \\
15 \\
16 \\
17\end{array}$ & $\begin{array}{l}50 \cdot 2 \\
47 \cdot 6 \\
47 \cdot 4 \\
45 \cdot 7 \\
48 \cdot 0 \\
46 \cdot 0 \\
44 \cdot 1 \\
44 \cdot 8 \\
47.0 \\
59 \cdot 2 \\
49 \cdot 6 \\
58 \cdot 5 \\
51 \cdot 3 \\
37 \cdot 5 \\
57 \cdot 1 \\
49 \cdot 0 \\
50 \cdot 9 \\
57 \cdot 3\end{array}$ & $\begin{array}{l}42.2 \\
39.7 \\
40.5 \\
44.5 \\
53.3 \\
49.7 \\
48.4 \\
46.5 \\
45.5 \\
49.9 \\
49.0 \\
55.5 \\
45 \cdot 6 \\
38.7 \\
54.8 \\
48.2 \\
50.6 \\
55.5\end{array}$ & $\begin{array}{l}53.2 \\
53.7 \\
53.2 \\
49.7 \\
50.8 \\
48.7 \\
49.6 \\
50.5 \\
48.8 \\
61.8 \\
52.5 \\
60.8 \\
54.4 \\
39.6 \\
58.5 \\
54.7 \\
52.3 \\
59.5\end{array}$ & $\begin{array}{l}48.8 \\
48.6 \\
49.0 \\
52.0 \\
57.1 \\
53.8 \\
50.6 \\
50.4 \\
49.7 \\
56.0 \\
52.4 \\
59.6 \\
50.5 \\
41.8 \\
57.0 \\
54.7 \\
52.2 \\
57.7\end{array}$ & $\begin{array}{l}3.0 \\
6.1 \\
5.8 \\
4.0 \\
2.8 \\
2.7 \\
5.5 \\
5.7 \\
1.8 \\
2.6 \\
2.9 \\
2.3 \\
3.1 \\
2.1 \\
1.4 \\
5.7 \\
1.4 \\
2.2\end{array}$ & $\begin{array}{l}6 \cdot 6^{1} \\
8 \cdot 9^{1} \\
8 \cdot 5^{1} \\
7 \cdot 5^{1} \\
3 \cdot 8^{1} \\
4 \cdot 1^{1} \\
2 \cdot 2^{1} \\
3 \cdot 9^{1} \\
4 \cdot 2^{1} \\
6 \cdot 1^{1} \\
3 \cdot 4 \\
4 \cdot 1^{1} \\
4 \cdot 9^{1} \\
3 \cdot 1^{1} \\
2 \cdot 2 \\
6 \cdot 5 \\
1 \cdot 6 \\
2 \cdot 2\end{array}$ & $\begin{array}{r}\overline{2} \\
20 \\
22 \\
14 \\
\overline{17} \\
22 \\
4 \\
0 \\
0 \\
0 \\
0 \\
0 \\
0 \\
0 \\
0\end{array}$ & $\begin{array}{l}33 \\
31 \\
37 \\
21 \\
14 \\
17 \\
24 \\
10 \cdot 5 \\
9 \\
5 \\
74 \\
0 \\
0 \\
5 \\
0 \\
0 \\
0\end{array}$ \\
\hline
\end{tabular}

$\mathbf{B}=$ Before nebulization. $\mathbf{A}=$ After nebulization. ${ }^{1}=\mathbf{P}<0.05$

tion). Assuming a normal distribution of variability, the $\mathrm{N}_{2}$ gradient would be different from the initial level with a difference greater than $0.72 \% \mathrm{~N}_{2}$ in individuals with normal gradient, or greater than $1.60 \% \mathrm{~N}_{2}$ in subjects with increased $\mathrm{N}_{2}$ gradient (mean plus two standard deviations). Both statistical methods give similar results except in subjects 4,5 , and 14, in whom the Student $t$ test did not disclose a statistically significant difference, owing to the dispersion and the reduced number of degrees of freedom. These are difficulties generally met with when applying statistical methods to individual subjects. We adopted the more severe criterion represented by the Student $t$ test. The appropriate method would be to determine the repeatability of the $\mathbf{N}_{2}$ gradient in each subject from this investigation, though this was not achieved.

The first seven subjects (including a repeated determination in subject 2) were characterized by a definite decrease of forced expiratory volume and vital capacity accompanied by dyspnoea, reflecting an induced asthmatic attack and wheezing. In these subjects $\mathbf{N}_{2}$ gradient was increased in five subjects (significantly in four) and (significantly) decreased in the remaining two. In subject \& 2 the $\mathrm{N}_{2}$ gradient was measured after 15 seconds' $\vec{\circ}$ acetylcholine nebulization and repeated after another 60 seconds' nebulization. After 15 seconds the $\mathrm{N}_{2}$ gradient rose from 5.8 to $7.5 \%$ nitrogen (the forced expiratory volume was reduced by $x$ $7 \%$ only); after one minute's nebulization there was a further rise in the $\mathrm{N}_{2}$ gradient (to $8.5 \%$ ), associated this time with a definite reduction in F.E.V.1.0 $(-37 \%)$.

Subject $8 \mathrm{had}$ an equivocal decrease of the F.E.V. $\cdot \cdot \cdot 0(-9 \%)$, while the $\mathrm{N}_{2}$ gradient rose from $\vec{Z}$ 1.8 to 4.2 (significant increase). Similarly, subject 9 experienced after acetylcholine moderate dyspnoea not reflected by the spirographic tests, but determining a great increase in the $\mathbf{N}_{2}$ gradient from $2 \cdot 6 \%$ to $6 \cdot 1 \%$. In such a case, using only the F.E. $V_{1 \cdot 0}$, the response would have been considered negative and dyspnoea overlooked. In subject 10 severe dyspnoea occurred after acetylcholine, preventing the recording of the spirographic parameters ; however, the $\mathrm{N}_{2}$ gradient rose from 2.9 to only $3.4 \%$ (non-significant increase).

In the last seven subjects (11 to 17$)$ the F.E.V.1.0 and V.C. were not significantly affected by bronchoconstrictor agents; $\mathrm{N}_{2}$ gradient rose by a significant amount in three $(11,12$, and 13), not significantly in another three $(14,15$, and 16), and was equal to its starting level in subject 17 .

In subject 2 wheezing with dyspnoea was produced on two different occasions. In one, beside the single breath $\mathrm{O}_{2}$ test, the residual volume was measured using the single breath method (McGrath and Thomson, 1959) with a bag in box system and a $1.5 \%$ mixture of helium in air. Vital capacity decreased after acetylcholine (from 3,800 $\mathrm{ml}$. to $2,400 \mathrm{ml}$.) ; a concomitant increase in residual volume (from 2,700 to $4,200 \mathrm{ml}$.) was recorded. Total lung capacity as measured by this $N$ technique remained unchanged. On two occasions the $\mathrm{N}_{2}$ concentrations at $750 \mathrm{ml}$. and $1,250 \mathrm{ml}$. expirate air were decreased after nebulization: from 47.4 to $40.5 \%$ at $750 \mathrm{ml}$. and from 53.2 to $49.0 \%$ at $1,250 \mathrm{ml}$. The same pattern was also found in cases $1,9,11,12,14$, and 17. However, $\mathrm{N}_{2}$ concentrations remained unchanged in one subject (10) and increased at both $750 \mathrm{ml}$. and $1,250 \mathrm{ml}$. in another three $(4,5$, and 13$)$. In the remaining cases the decrease in the $\mathrm{N}_{2}$ concentrations at $750 \mathrm{ml}$. was accompanied by a variable response at $1,250 \mathrm{ml}$. expirate air. 


\section{DISCUSSION}

The single breath $\mathrm{O}_{2}$ test proposed in 1951 by Comroe and Fowler as an objective and simple method for the assessment of uneven ventilation acquired a wide popularity, especially after its standardization by Kjellmer et al. (1959).

Previous studies (Raine and Bishop, 1964 ; Norris and Bishop, 1966) showed an increase in the slope of the nitrogen plateau after carbachol and calcium carbonate dust in normal subjects, 'reactors', and patients with chronic bronchitis and bronchial asthma. However, only the mean value of the $\mathrm{N}_{2}$ gradient was reported.

Our results indicate that an induced asthmatic attack does not result in a unique pattern of response in the single breath test.

It should be mentioned that F.E.V $\cdot_{\cdot 1 \cdot 0}$ and $\mathrm{N}_{2}$ gradient do not reflect the same phenomenon. The reduction of F.E.V.1.0 is assumed to reflect indirectly an increase of the airway resistance, but this assumption may be in error (Macklem and Mead, 1967); and a reduction does not indicate whether the decrease in resistance is diffuse or local.

Malmberg et al. (1963) found a significant correlation between $\mathbf{N}_{2}$ gradient and forced expiratory volume in chronic bronchitis. In 85 subjects with chronic obstructive lung disease a similar correlation between increased $\mathrm{N}_{2}$ gradient and decreased F.E.V.1.0 was observed in our laboratory (unpublished observations). Other authors, using the lung clearance index (Bouhuys et al., 1960b) or a method to assess asynchronous ventilation (Petit, 1965), found an impairment of ventilation distribution during induced asthma attacks. The increase in the $\mathrm{N}_{2}$ gradient in patients whose F.E.V.$_{1 \cdot 0}$ decreased significantly justify these premises indicating a more uneven alveolar ventilation as a consequence of the asthmatic attack.

The decrease of the $\mathrm{N}_{2}$ gradient was an unexpected finding. The drop of the $\mathrm{N}_{2}$ gradient, concomitantly with the increase of the nitrogen concentration at $750 \mathrm{ml}$. expired air, might be explained by the preferential distribution of bronchoconstrictive drugs to units with patent airways, resulting in better ventilation of these units (which empty first). The final result is an apparent improvement of the distribution. The question why the proposed mechanism did not operate in other cases cannot be confidently answered.

In patient 2 an increase in the alveolar nitrogen concentration would have been reasonably expected, as a consequence of the increase in residual volume. In fact the reverse was observed. An explanation could be the failure of inspired oxy- gen to mix with the alveolar nitrogen as a result of a concentration gradient. The alternative explanation is closure of airways at functional residual capacity and opening during maximal inspiration, as advanced by Bouhuys et al. (1960a). The present results do not allow a choice of one or other of these theories; however, the first assumption seems to us more plausible.

In fact, so far there is no general agreement concerning the interpretation of the alveolar slope in health and disease. Otis, McKerrow, Bartlett, Mead, McIlroy, Selverstone, and Radford (1956) considered that both compliance and resistance of different pulmonary units determine the distribution pattern. Uhits having a small time constant would be well ventilated and would expire early; large time constant units would be poorly ventilated and would expire late-first in, first out theory. The first in, last out theory proposed by Fowler (1952) considers that gas distribution is sequentially distributed in relation to time ; units filling early in inspiration empty late in expiration. This concept has received much support, although the conclusion drawn from these studies (Koler, Young, and Martin, 1959; Fowler, 1964 ; Young and Martin, 1966), including an elaborated radioactive gas technique (Bates, Kaneko, Henderson, Milic-Emili, Anthonisen, Dollfuss, and Dolovich, 1966 ; Pain, Glazier, Simon, and West, 1967) cannot be easily applied to the particular procedure of the single breath $\mathrm{O}_{2}$ test.

Although the single breath $\mathrm{O}_{2}$ test was standardized by Kjellmer et al. (1959), there are still some factors (Shephard, 1956; Thomson, Shephard, McGrath, and Thornton, 1964 ; Nesarajah, 1965 ; Mills and Harris, 1965) that can influence the $\mathrm{N}_{2}$ gradient. The inspired or expired flow, as currently measured, is a mean flow and not an instantaneous flow. Young, Martin, and Pace (1963) observed variable results, depending on instantaneous expiratory flow rate.

Another fact that complicates the interpretation of the nitrogen slope is represented by the regional differences in ventilation/perfusion ratio, resulting in an initial non-uniform distribution of alveolar nitrogen.

Recently, Cumming, Crank, Horsfield, and Parker (1966) and Sikand, Cerretelli, and Farhi (1966), using different approaches, demonstrated that in normal man the slope of the alveolar plateau can be determined by a diffusion gradient in airways, as originally suggested by Krogh and Lindhard (the stratification theory).

The part played by the series and parallel ventilation was found in normal subjects to be dif- 
ferent when the test is performed near to residual volume or above this level (Jones, 1967). In the present study the lung volume at which the test was performed was not controlled. Residual volume was shown to increase following constricting aerosols (Lovejoy, Constantine, Flatley, Kaltreider, and Dautrebande, 1961). The variable volume at which our subjects performed the single breath manœuvre before and after bronchoconstrictor aerosols could probably be in part responsible for the modification of the $\mathbf{N}_{2}$ slope. However, it is hazardous to extrapolate results of normal subjects to patients with pulmonary inhomogeneity. The mechanisms determining the change in alveolar plateau in normals in relation to lung volume may $a$ priori be different from those acting after bronchoconstrictor aerosols. The present study does not allow a distinction between regional inhomogeneity and gas mixing defect to be drawn.

The main advantage from a practical point of view of the single breath oxygen test in detecting induced dyspnoea with wheezing is its objectivity; besides it is easy to perform (good acceptability). These characteristics make the test useful, especially in uncooperative subjects or malingerers. The significant increase in the $\mathrm{N}_{2}$ gradient in the absence of ventilatory impairment emphasizes the sensitivity of this method. However, the variable behaviour of the $\mathrm{N}_{2}$ gradient in cases with 'asthmatic attacks' with significant F.E.V.1.0 decrease limits the utilization of the single breath $\mathrm{O}_{2}$ test in assessing the response to bronchoconstrictive drugs. Owing to its sensitivity this test can be applied together with the spirographic measurements. A significant increase of the $\mathbf{N}_{2}$ gradient accompanying a definite decrease of the forced expiratory volume strongly supports the result of spirographic tests, conferring to them an additional objectivity. A decreased or an unchanged $\mathrm{N}_{2}$ gradient does not refute the positive spirographic test. In patients with unchanged forced expiratory volume a significant increase of the $\mathbf{N}_{2}$ gradient, whether or not associated with slight dyspnoea, suggests a minor asthmatic attack, not reflected by the less sensitive spirographic tets.

The authors wish to express their gratitude to $\mathrm{Dr}$ M. Steinbach (Statistics Centre of Rumanian Academy of Sciences) for fruitful discussion and suggestions concerning the statistical procedures.

\section{REFERENCES}

Bates, D. V., Kaneko, K., Henderson, J. A. M., Milic-Emili, J., Anthonisen, N. R., Dollfuss, R., and Dolovich, M. (1966). Recent experimental and clinical experience in studies of regional Recent experimental and clinical experience in studes of
lung function. Scand. J. resp. Dis., Suppl. No. 62, p. 15.
Bernstem, L., Kreindler, A., and Sugeman, D. (1964). Direct bronchial testing in allergy. I. Preliminary results concerning utility, validity and safety of the technique in treated and untreated asthmatic patients. Ann. Allergy, 22, 49.

Bouhuys, A., Georg, J., Jönsson, R., Lundin, G., and Lindell, S. E. (1960a). The influence of histamine inhalation on the pulmonary diffusing capacity in man. J. Physiol. (Lond.), 152, 176.

- Jc̈nsson, R., Lichtneckert, S., Lindell, S. E., Lundgren, C., Lundin, G., and Ringquist, T. R. (1960b). Effects of histamine on pulmonary ventilation in man. Clin. Sci., 19, 79.

Citron, K. M., Frankland, A. W., and Sinclair, J. D. (1958). Inhalation tests of bronchial hypersensitivity in pollen asthma. Thorax, 13, 229.

Colldahl, H., Nisell, O., Ripe, C., and Svanborg, N. (1960). Studies on the registration of provocation tests for the etiological diagnosis of bronchial asthma. Acta allerg. (Kbh.), 15, 395.

Comroe, J. H., and Fowler, W. S. (1951). Lung function studies. VI. Detection of uneven alveolar ventilation during a single breath of oxygen. Amer. J. Med., 10, 408.

Cumming, G., Crank, J., Horsfield, K., and Parker, I. (1966). Gaseous diffusion in the airways of the human lung. Resp. Physiol., 1, 58

Fagerberg, F. (1966). Allergen inhalation tests on patients suffering from bronchial asthma estimated by measuring maximum expiratory flow. Acta allerg. (Kbh.), 21, 155.

Fowler, K. T. (1964). Relative compliances of well and poorly ventilated spaces in the normal human lung. J. appl. Physiol. $19,937$.

Fowler, W. S. (1952). Intrapulmonary distribution of inspired gas. Physiol. Rev., 32, 1.

Herxheimer, H. (1951). Bronchial obstruction induced by allergens, histamine and acetyl-beta-methylcholinechloride. Int. Arch. Allergy, 2, 27.

Jones, J. G. (1967). The effect of preinspiratory lung volume on the result of the single breath $\mathrm{O}_{2}$ test. Resp. Physiol., 2, 375.

Kim, Chong-Jin (1965). The bronchial provocation test: Its clinical evaluation and the course of induced asthma. J. Allergy, 36, 353

Kjellmer, I., Sandqvist, L., and Berglund, E. (1959). "Alveolar plateau" of the single breath nitrogen elimination curve in normal subjects. J. appl. Physiol., 14, 105.

Koler, J. J., Young, A. C., and Martin, C. J. (1959). Relative volume changes between lobes of the lung. Ibid., 14, 345 .

Lovejoy, F. W., Constantine, H., Flatley, J., Kaltreider, N., and Dautrebande, L. (1961). Measurement of gas trapped in the lungs during acute changes in airway resistance in normal subjects and in patients with chronic pulmonary disease. Amer.J. Med., 30,884.

McAllen, M. K. (1961). Bronchial sensitivity testing in asthma. Thorax, 16, 30.

McGrath, M. W., and Thomson, M. L. (1959). The effect of age body size and lung volume change in alveolar-capillary permeability and diffusing capacity in man. J. Physiol. (Lond.), 146, 572.

Macklem, P. T., and Mead, J. (1967). The physiological basis of common pulmonary function tests. Arch. environm. Hlth, 14, 5 .

Malmberg, R., Simonsson, B., and Berglund, E. (1963). Airways obstruction and uneven gas distribution in the lung. Thorax, 18 168.

Marcelle, R., and Petit, J. M. (1965). Intérêt comparé des différentes techniques de mise en évidence des réactions bronchiques au cours des tests de provocation chez l'asthmatique. Acta clin. belg., $20,81$.

Medical Research Council (1965). Committee on the Aetiology of Chronic Bronchitis: Definition and classification of chronic bronchitis for clinical and epidemiological purposes. Lancet, 1 , 775.

Mills, R. J., and Harris, P. (1965). Factors influencing the concentration of expired nitrogen after a breath of oxygen. J. appl. Physiol. $20,103$.

Nesarajah, M. S. (1965). Factors influencing the measurement of inequalities of ventilation and of ventilation-perfusion ratio in the lung by the single breath test. J. Physiol. (Lond.), 181, $71 P$.

Nilsson, H., and Kaude, J. (1960). Inhalation and skin test in the diagnosis of asthma bronchiale. Dis. Chest, 37,535 .

Norris, R. M., and Bishop, J. M. (1966). The effect of calcium carbonate dust on ventilation and respiratory gas exchange in normal subjects and in patients with asthma and chronic bronchitis. subjects and in pat.
Clin. Sci, 103.

Olsen, H. C., and Gilson, J. C. (1960). Respiratory symptoms, bronchitis, and ventilatory capacity in men. Brit. med.J., 1, 450.

Otis, A. B., McKerrow, C. B., Bartlett, R. A., Mead, J., McIlroy, M. B. Selverstone, N. J., and Radford, E. P., Jr. (1956). Mechanica factors in distribution of pulmonary ventilation. J. appl. Physiol. $8,427$.

Pain, M. C. F., Glazier, J. B., Simon, H., and West, J. B. (1967) Regional and overall inequality of ventilation and blood flow in patients with chronic airflow obstruction. Thorax, 22, 453. 
Petit, J. M. (1965). Physiopathologie de la dyspnée chez l'asthmatique. Thesis, University of Liège, Ed. Arscia, Brussels.

Raine, J. M., and Bishop, J. M. (1964). Alterations in ventilationperfusion relationships in the lung after breathing inert dust or bronchoconstrictor aerosols and after short periods of voluntary hyperventilation. J. clin. Invest., 43, 557.

Sandqvist, L., and Kjellmer, I. (1960). Normal values for the single breath nitrogen elimination test in different age groups. Scand. breath nitrogen elimination
J. clin. Lab. Invest., 12, 131 .

Scherrer, M. (1966). Die Lungenfunktionsstörung beim akuten Anfall von Asthma bronchiale. Schweiz. med. Wschr., 96, 935.

Shephard, R. J. (1956). Assessment of ventilatory efficiency by the single-breath technique. J. Physiol. (Lond.), 134, 630.

Sikand, R., Cerretelli, P., and Farhi, L. E. (1966). Effects of $\dot{V}_{A}$ and $V_{A} / Q$ distribution and of time on the alveolar plateau. J. appl. Physiol., 21, 1331.

Stanescu, D. C., Teculescu, D. B., Pacuraru, R., and Gavrilescu, N. (1968a). Chronic effect of smoking upon pulmonary distribution of ventilation in healthy males. Respiration, 25, 497. breath $\mathrm{O}_{2}$ test. (To be published.)

Thomson, M. L., Shephard, R. J., McGrath M. W., and Thornton, V. A. (1964). The merits of oxygen, air, and helium as singlebreath indicators of nonuniform distribution of inspired gas. Amer. Rev. resp. Dis., 89, 859.
Tiffeneau, R. (1959). De l'allergie pulmonaire à l'hyperexcitabilite bronchomotrice de l'asthmatique. Presse méd., 67, 2017.

Young, A. C., and Martin, C. J. (1966). The sequence of lobar emptying in man. Resp. Physiol., 1, 372.

- and Pace, W. R. (1963). Effect of expiratory flow patterns on lung emptying. J. appl. Physiol., 18, 47.

\section{ADDENDUM}

After the completion of this work a paper was published by Colldahl, Pegelow, and Pokorny (1967). All the 10 asthmatic patients studied showed an increase of the $\mathrm{N}_{2}$ gradient during induced attacks.

\section{REFERENCE.}

Colldahl, H., Pegelow, K. O., and Pokorny, J. (1967). The singlebreath nitrogen-elimination test for the registration of provocation tests in allergy diagnosis. Acta allerg. (Kbh.), 22, Suppl. 8, p. 79. 